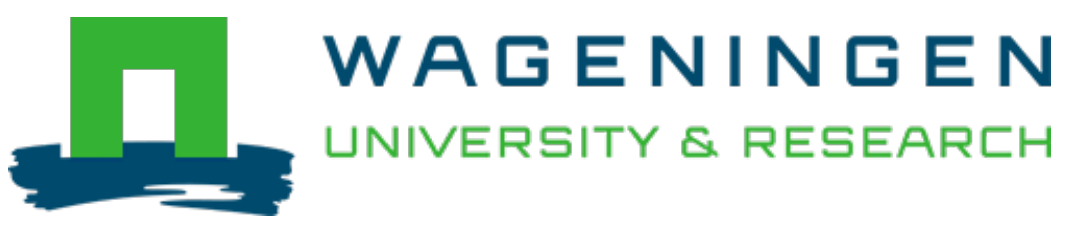

\title{
Peer feedback or peer feedforward? Enhancing students' argumentative peer learning processes and outcomes
}

\author{
British Journal of Educational Technology \\ Latifi, Saeed; Noroozi, Omid; Talaee, Ebrahim \\ https://doi.org/10.1111/bjet.13054
}

This article is made publicly available in the institutional repository of Wageningen University and Research, under the terms of article $25 \mathrm{fa}$ of the Dutch Copyright Act, also known as the Amendment Taverne. This has been done with explicit consent by the author.

Article 25 fa states that the author of a short scientific work funded either wholly or partially by Dutch public funds is entitled to make that work publicly available for no consideration following a reasonable period of time after the work was first published, provided that clear reference is made to the source of the first publication of the work.

This publication is distributed under The Association of Universities in the Netherlands (VSNU) 'Article $25 \mathrm{fa}$ implementation' project. In this project research outputs of researchers employed by Dutch Universities that comply with the legal requirements of Article $25 \mathrm{fa}$ of the Dutch Copyright Act are distributed online and free of cost or other barriers in institutional repositories. Research outputs are distributed six months after their first online publication in the original published version and with proper attribution to the source of the original publication.

You are permitted to download and use the publication for personal purposes. All rights remain with the author(s) and / or copyright owner(s) of this work. Any use of the publication or parts of it other than authorised under article $25 \mathrm{fa}$ of the Dutch Copyright act is prohibited. Wageningen University \& Research and the author(s) of this publication shall not be held responsible or liable for any damages resulting from your (re)use of this publication.

For questions regarding the public availability of this article please contact openscience.library@,wur.nl 


\title{
Peer feedback or peer feedforward? Enhancing students' argumentative peer learning processes and outcomes
}

\section{Saeed Latifi, Omid Noroozi and Ebrahim Talaee}

Saeed Latifi is a lecturer at Kharazmi University, Iran. His research interests include Peer Feedback, E-Learning and Distance Education, Computer-Supported Collaborative Learning (CSCL), Argumentative Knowledge Construction in CSCL, Argumentation-Based CSCL, CSCL Scripts and Transactivity. Omid Noroozi is an Associate Professor at the Education and Learning Sciences Chair Group, Wageningen University and Research, The Netherlands. His research interests include Peer Feedback, Collaborative Learning, E-Learning and Distance Education, Computer-Supported Collaborative Learning (CSCL), Argumentative Knowledge Construction in CSCL, Argumentation-Based CSCL, CSCL Scripts and Transactivity. Ebrahim Talaee is a faculty member of Educational Technology at Tarbiat Modares University, Iran. His research interests include Educational Technology, Peer Feedback, E-Learning and Distance Education, Curriculum Design and Development. Address for correspondence: Saeed Latifi, Kharazmi University, Tehran, Iran.Email: saeed.latifi@gmail.com

\begin{abstract}
This study compared the effects of support for peer feedback, peer feedforward and their combination on students' peer learning processes, argumentative essay quality and domain-specific learning. Participants were 86 BSc students who were randomly divided over 43 dyads. These dyads, in a two-factorial experimental design, were assigned to four conditions including: peer feedback $(n=22)$, peer feedforward $(n=22)$, mixed $(n=20)$ and control group $(\mathrm{n}=22)$ conditions. An online peer feedback environment named EduTech was designed which allowed us to implement various types of support in the form of question prompts. In this online environment, students were asked to write an argumentative essay on a controversial topic, to engage in peer learning processes and to revise their essay. Overall, the results showed that students in the three experimental conditions (peer feedback, peer feedforward and their combination) benefited more than students in the control group condition (without any support) in term of peer learning processes, argumentative essay quality and domain-specific learning. However, there was no significant difference among the three experimental conditions. This implies that peer feedforward can be as important as peer feedback in collaborative learning environments which is often neglected both in theory and practice.
\end{abstract}

Keywords: argumentative essay writing, domain-specific learning, peer feedback, peer feedforward, peer learning

\section{Introduction}

Undergraduate students are often tasked with writing argumentative essays when they deal with complex and controversial issues (see Noroozi, Biemans, \& Mulder, 2016). Inclusion and development of arguments are key features of each successful essay (Wingate, 2012). Many scholars emphasize that writing argumentative essays on controversial topics in any given domain requires students to provide a clear position on the issue as their main claim, supported with logical evidence and followed by counter-arguments against the main claim. Furthermore, the 


\section{Practitioner Notes}

What is already known about this topic?

- Writing argumentative essays is a common practice for higher education students in various disciplines which deal with controversial issues.

- Writing argumentative essay requires solid argumentation strategies which makes it a challenging task for higher education students.

- Additional instructional support is needed to help students write high-quality argumentative essays.

What this paper adds?

- Peer learning is a promising instructional strategy for improving students' argumentative essay writing and learning.

- Online support in the form of question prompts to guide students during peer learning can improve their argumentative essay writing and learning.

- Next to the peer feedback, peer feedforward is also a promising instructional approach to support students' argumentative essay writing and learning.

Implications for practice and/or policy

- Given the positive effects of peer learning processes, the use of peer feedback and peer feedforward should be given more attention by teachers to support students write high-quality argumentative essays for controversial issues.

- Teachers and educational designers should not only provide opportunities for students to engage in peer feedback processes (how I am doing?) but also in peer feedforward processes (where to next?).

essay needs integration of pros and cons of the issue at stake leading to a general conclusion on the issue (see Latifi, Noroozi, Hatami, \& Biemans, 2019; Noroozi et al., 2016). This suggests that argumentative essay writing needs solid argumentation and reasoning strategies (Wingate, 2012). Unfortunately, many higher education students struggle with including and developing such argumentation strategies in their essays (Wingate, 2012). Teachers often complain about the lack of structure sound argumentation and solid reasoning in students' argumentative essays (Kellogg \& Whiteford, 2009).

Various factors may contribute to the poor quality of students' argumentative essays: First, some students may lack knowledge of the features and structure of argumentative essay (Bacha, 2010; Wingate, 2012). Hence, they may deal with difficulties in applying these features when writing essays (Noroozi et al., 2016). Second, since the nature of argumentative essays could be different across and even within disciplines (Wingate, 2012), the process of transferring argumentation knowledge from one domain to another could be troublesome (see Noroozi, Kirschner, Biemans, \& Mulder, 2018; Wingate, 2012). Third, writing argumentative essays is cognitively demanding (Crowhurst, 1990) which imposes large amount of intrinsic cognitive load on learners. The reason is that applying solid argumentation and reasoning in written essays requires students to engage in deep and critical cognitive elaboration of the materials that can take into account the opinions of both opponents and proponents of the issue at stake (see Noroozi, 2018). These issues suggest that higher education students need additional support on how to write sound argumentative essays that include solid argumentation and reasoning strategies on controversial issues. Peer learning has been considered as one of the most promising approaches that can be used for supporting students to write high-quality argumentative essays (see Latifi et al., 2019). 
Theoretically, peer learning is related to Vygotsky's sociocultural theory (Vygotsky, 1962), explaining that human learning is mainly a social and cultural process that occurs through meaningful negotiation and interaction between learners (see Rahimi, 2013). From this perspective, learning is socially constructed during interaction and activity with others (Vygotsky, 1978). In this study, peer learning is considered as knowledge acquisition and learning through provision of feedback and feedforward to learning peers and also reception of peer feedback and feedforward from equal-status students. Peer learning can be conducted in real educational settings by equal-status students who are not professional teachers trying to help each other and paying compliments on their knowledge to learn together (Topping, 2005). Peer learning has recently been used as a highly flexible and applicable strategy for improving a wide variety of processes or outcomes of task performance, including improving quality of students' writing (Huisman, Saab, van den Broek, \& van Driel, 2018; Ion, Barrera-Corominas, \& Tomàs-Folch, 2016; Min, 2006; Topping, 2009) and domain-specific learning (Latifi et al., 2019; Noroozi \& Mulder, 2017; Valero Haro, Noroozi, Biemans, \& Mulder, 2018).

The effectiveness of peer learning has been widely reported in various empirical studies (see Noroozi \& Mulder, 2017). With practice through peer learning, students are enabled to promote their ability to detect, diagnose and solve writing problems (Liu \& Carless, 2006; Patchan \& Schunn, 2015). By comparing their own writing with peers, students are enabled to broaden and deepen their reflective thinking (Yang, 2010) and critical thinking and understanding about the topic (see Noroozi et al., 2016). Peer learning promotes a sense of audience, boosts learners' knowledge of their own strengths and shortcomings and provides opportunities for collaborative learning (Tsui \& Ng, 2000; Xiao \& Lucking, 2008). Therefore, in the long-term, with peer learning students become more independent and active learners and less reliant on the teacher (Tsui \& Ng, 2000). This in turn leads to more confident students who can acquire metacognitive, monitoring and self-regulation skills (Earl, 2003). Previous literature report that peer learning practices lead to improvements of students' self-monitoring skills and performance independently of the teacher (see Nicol \& Macfarlane-Dick, 2006; Van den Boom, Paas, \& van Merriënboer, 2007).

Asking students to engage in peer learning process without appropriate support and clear criteria does not lead to successful learning performance especially when it comes to writing argumentative essays and learning from such essays. Some instructors claim that students might not be able to go beyond surface level feedback during peer learning (Cho \& Schunn, 2007). This is especially the case with novice students with less expertise who mostly struggle to provide detailed and high-quality feedback to their peers. Furthermore, peer learning can be biased because of variation in students' prior knowledge, peer characteristics, personal preferences and relationships with the peers (Dijks, Brummer, \& Kostons, 2018). Hence, such variation may affect the validity of the peer learning (see Liu \& Carless, 2006).

The most important challenge for peer learning is that most students focus on responding to the actual task with respect to the actual performance of their learning peers (peer feedback). In most cases, students do not provide information on possible directions or strategies (peer feedforward) for their learning peers to attain the desired goal (see Noroozi \& Hatami, 2019). One may argue that in practice peer feedforward is already embedded in the peer feedback practices. This is basically what we expect from a typical peer learning process but scientific evidence shows that this is not the case and students often ignore giving direction on "where to next" and mostly focus on "how am I doing."

This is striking since peer learning should not only focus on peer's actual work and performance (how I am doing?) but also indicating a direction by delineating a goal to be attained (where to next?) (see Hattie \& Timperley, 2007). From this perspective, peer learning can be more effective 
when the feedback also includes information about the progress and more importantly how to proceed (Hattie \& Timperley, 2007). This implies that peer learning can take place in the form of feedback, feedforward or both. This is especially important because nowadays educational technologies allow teachers to easily embed both peer feedback and peer feedforward question prompts in the learning environment. For example, such incorporation of peer feedback and peer feedforward can be done through computer-supported collaborative learning environments (see Noroozi, Kirschner, et al., 2018) to help learners complement each other's information on the topic and co-construct knowledge together. Online learning environments can be designed in such a way to provide students with the opportunity to not only reflect on the actual work and performance of their peers (peer feedback), but also reflect and provide directions to their peers towards achieving the desired goal. Implementation of peer learning through online environments provide various opportunities for peer learning which are not possible in the traditional face to face environments. Online learning environments enable teachers to remove students' identification and hereby provide students with an opportunity to engage in anonymous peer learning processes, ie, giving and receiving feedback and feedforward from peers anonymously (Nicol, Thomson, \& Breslin, 2014). When peer feedback is not applied anonymously, there is always a possibility for students to fall into undesirable social bias based on their friendships and/ or other social relationships and/or experience conflicts. Such bias can affect students' learning and their attitudes towards peer learning (see Lin, 2018). Preventing or reducing undesirable social bias may result in a deeper critical peer learning processes (Lin, Liu, \& Yuan, 2001). Such anonymity also seems to influence the content of comments during peer learning (Dijks et al., 2018). Lin (2018) indicates that when peer review is anonymous, students significantly provide more cognitive comments than affective comments. This is important since high-quality peer learning processes typically include deep cognitive processing (King, 2002).

Engaging in peer feedback and peer feedforward processes can be time consuming especially when students are not accustomed to the clear criteria for peer learning processes in traditional settings (Rollinson, 2005). Students need to spend a significant amount of time on thinking, analyzing and criticizing their peers' works (Liu \& Carless, 2006). Traditional educational settings may not always accommodate such clear criteria and enough time for students and, as a result, the potential of peer learning may not be fully attained. Online environments allow for embedding various types of clear criteria for example, through question prompts that can guide students to provide their peers with more reliable, valid and relevant feedback and feedforward (Latifi et al., 2019; Noroozi, Biemans, Busstra, Mulder, \& Chizari, 2011; Noroozi et al., 2016). Scientific research reveal positive outcomes of providing students with clear criteria during peer learning on quality of students' peer learning processes, argumentative essay writing and domain-specific knowledge learning (see Latifi et al., 2019; Noroozi et al., 2016; Valero Haro et al., 2018, Gielen \& Wever, 2015).

To summarize, previous research has shown that engaging in high-quality peer learning processes can enhance essay writing quality (Gielen \& De Wever, 2015; Noroozi et al., 2016). There is not yet empirical research comparing the effects of support for the feedback, feedforward and their combination on various aspects of learning processes and outcomes of argumentative essay writing. The picture is unclear whether provision of feedback on the actual task is more beneficial or rather provision of feedforward on the possible direction towards achieving the desired goal. Thus, in this study, we aim to compare the effects of support for the peer feedback, peer feedforward and their combination on students' peer learning processes, argumentative essay quality and domain-specific learning. We have formulated following questions to achieve the main goal of this empirical study: 
1. What are the effects of support for the peer feedback, peer feedforward and their combination on students' quality of peer learning processes?

2. What are the effects of support for the peer feedback, peer feedforward and their combination on students' quality of argumentative essay writing?

3. What are the effects of support for the peer feedback, peer feedforward and their combination on students' domain-specific knowledge learning?

\section{Methods}

\section{Context and participants}

The study took place at Kharazmi University, Tehran, Iran. Participants consisted of 86 BSc students who enrolled for the course "Applying Computer in the Educational Sciences" and were randomly divided over 43 dyads. These dyads, in a two-factorial experimental design, were assigned to four conditions including: peer feedback $(n=22)$, peer feedforward $(n=22)$, mixed $(n=20)$ and control group $(n=22)$ conditions. The mean age of the students were $20.02(\mathrm{SD}=1.75)$ years. All participants were female.

In this study, participants were supposed to write argumentative essays within their own discipline and with their mother tongue, Persian. Prior to this course, students did not have any experience regarding argumentative essay writing. Prior to this study, students received a short instruction on various types of essays (such as narrative, descriptive, expository, procedural and persuasive essays) in a form of lecture and then, were given the task of writing an argumentative essay included in the online platform, EduTech, of this study.

\section{Learning task and procedure}

The content of learning was "Mobile Learning." Students were asked to write a draft argumentative essay on the following statement: Should mobile phones be banned in classrooms? Then, they were asked to engage in peer learning processes (ie, giving and receiving feedback or feedforward or their combination) and finally they were tasked with revising their original essay draft based on the input received from their learning partner. All the activities of students in the four conditions were implemented through an online asynchronous platform named EduTech. The students' learning activities in EduTech were counted for 50\% of the students' final grade for the course. EduTech had a series of phases (see Figure 1). The study was conducted in five sessions over five consecutive weeks. The first and the last sessions each lasted approximately for 30 minutes. The second, third and fourth sessions each lasted approximately for 80 minutes (see Figure 1).

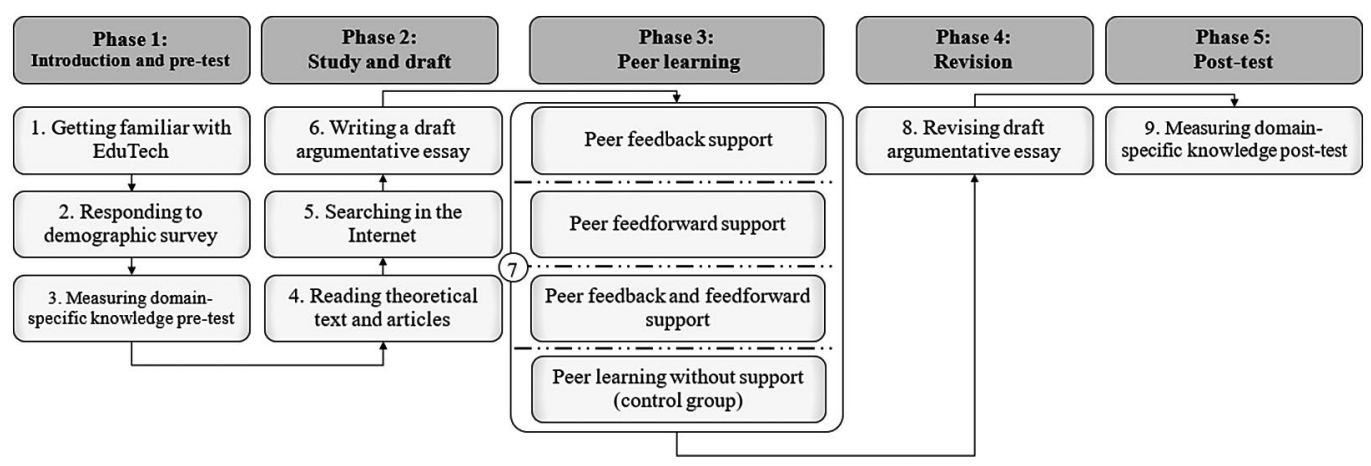

Figure 1: The procedure in the EduTech environment for students in four conditions 


\section{EduTech: The online peer learning platform}

An online learning environment named EduTech was designed and used in this study. EduTech (http://www.edutechcscl.ir/) is a web-enabled platform that provides students with various forms of media, such as texts, exercises, graphs, diagrams and pictures with the peer learning features (peer feedback and peer feedforward) to stimulate interactions between peers in an active learning environment. The set of question prompts during peer learning processes was the main feature of EduTech in the study. EduTech allows for scaffolding the peer learning processes and textual implementation of the question prompts. EduTech was designed in such a way to guide the interaction style for both synchronous and asynchronous interactions-promoting reasoning, critical discussion and justified arguments. The structure of the guided peer learning processes (ie, argumentative peer feedback, peer feedforward scripts and combination of both) was designed on the basis of argumentation literature (see Bacha, 2010; Leitão, 2003; Mei, 2006; Noroozi et al., 2016; Toulmin, 1958; Wingate, 2012; Wood, 2001) and a high-quality argumentative essay in the field of Educational Sciences.

\section{Experimental conditions}

Table 1 describes the types of support in the form of question prompts for each experimental condition. The first column shows various elements of an argumentative essay in the field of educational sciences. Students in the experimental conditions were supported with question prompts during their online peer learning processes. Students with the peer feedback support were provided with pre-structured feedback question prompts related to various aspects of an argumentative essay about the peers' actual task and/or performance (see Table 1, column 2). Students with the peer feedforward support were provided with pre-structured feedforward question prompts related to various aspects of an argumentative essay about possible directions or strategies to pursue towards reaching a desired goal (see Table 1, column 3). Students in the mixed condition were provided with pre-structured peer feedback and peer feedforward question prompts (see Table 1, column 4). The learning partners in the control group condition received no further support beyond being asked to type their feedback and/or feedforward into a blank text box during peer learning phase.

The question prompts were designed on the basis of literature (see Bacha, 2010; Leitão, 2003; Noroozi, 2018, Noroozi et al., 2016; Schneer, 2014; Toulmin, 1958; Wood, 2001; Wu, 2006). A panel of experts including various professors adjusted and validated various aspects of a typical argumentative essay in the field of educational sciences.

\section{Instruments}

We used an adjusted rubric designed by Noroozi et al. (2016) and Latifi et al. (2019) to measure the quality of students' argumentative peer learning processes and their argumentative essays. This rubric was built on the components of argumentation model (see Table 1). A single score was assigned for each component both for the peer learning processes and argumentative essay writing phases (draft and revised versions). In terms of quality of peer learning processes, zero point was assigned if the student did not provide any feedback related to the corresponding component of the argumentation model during peer learning phase (ie, not mentioned). One point was assigned if at least one comment was mentioned but not elaborated during peer learning (ie, non-elaborated). Two points were assigned if at least one comment was mentioned and elaborated during peer learning phase (ie, elaborated). Appendix 1 in supplementary material shows various items of the rubric.

The same coding strategy was applied for measuring the quality of argumentative essays both in the draft and also in the revised versions. For each of the components, students received a 


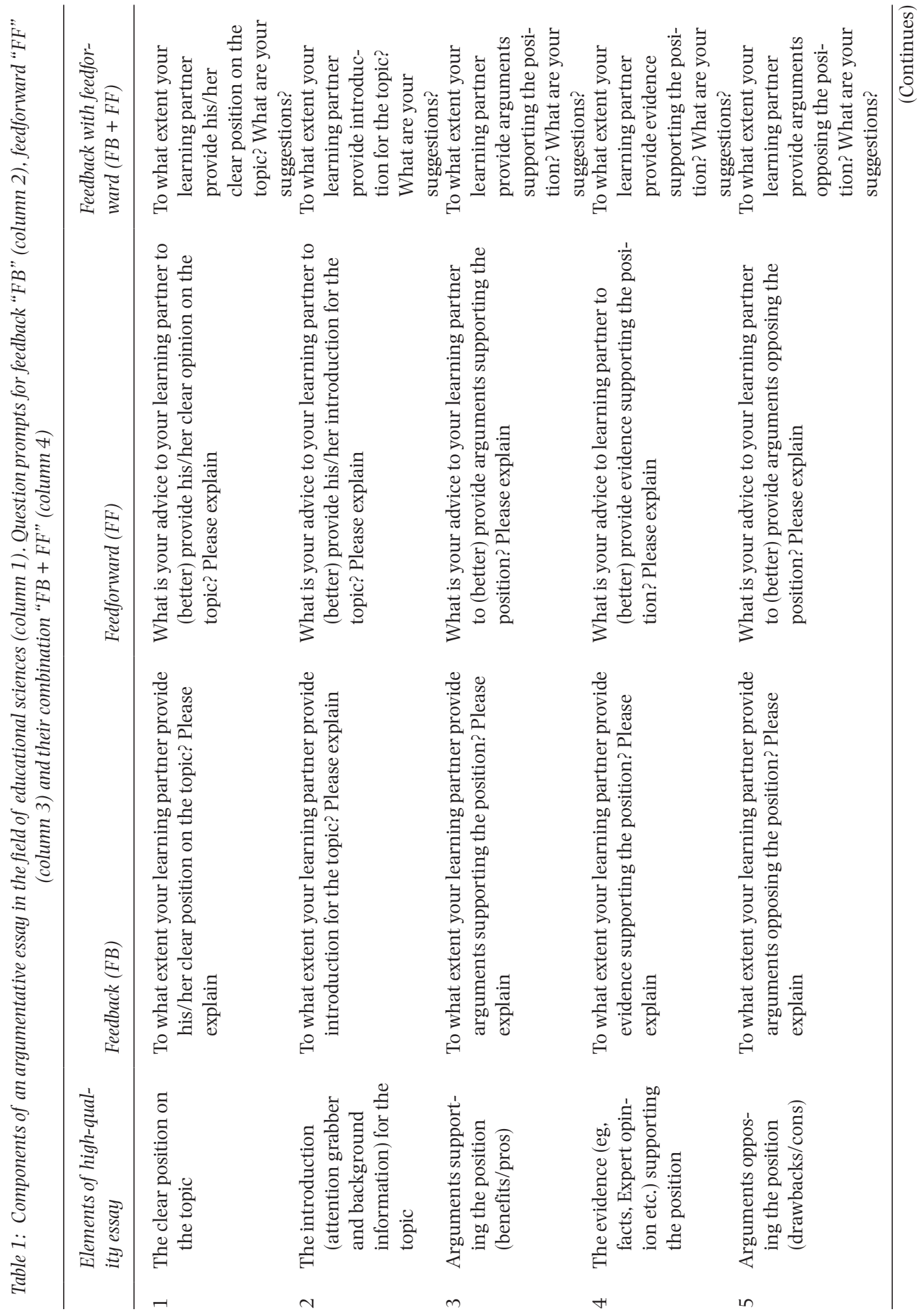




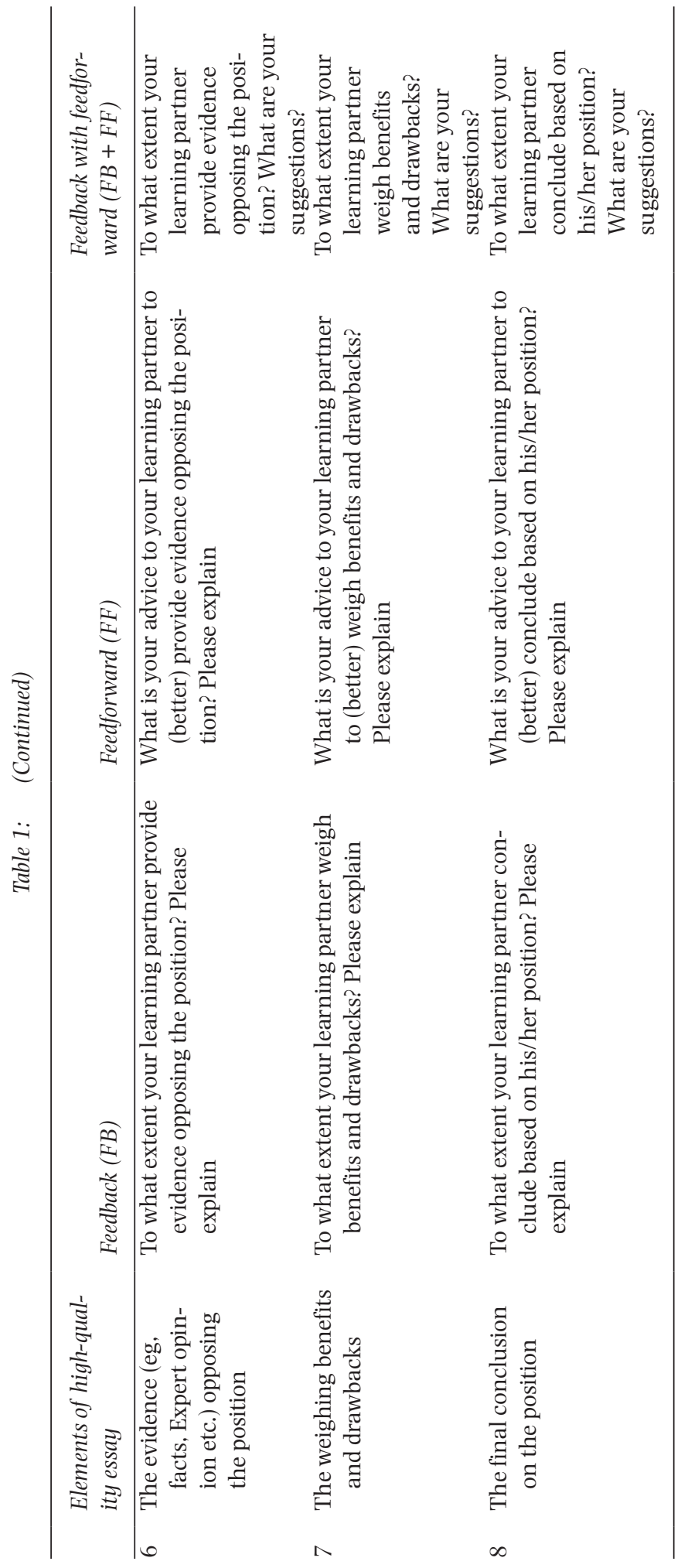


score between zero and two. Zero point was given if the student did not mention anything related to the corresponding component of the argumentation model at all. One point was given if the student provided at least one argument related to the corresponding component, and two points were given if the student provided at least one argument and also elaborated on that. Then, all points were added together serving as the final score indicating their quality of argumentative peer learning and their draft and revised argumentative essays. Appendix 2 in supplementary material shows various items of the rubric.

Two coders (the first author and also an experienced external coder with sufficient background and knowledge of the study) coded $10 \%$ of the data both in the peer learning, draft and revised phases to calculate Cohen's Kappa reliability index of inter-rater agreement. The results of Kappa's analysis showed comparable scores in $80 \%$ of the contributions in the peer learning phase, $86 \%$ of the contributions in the draft and $84 \%$ of the contributions in the revised versions. Discrepancies were resolved through discussion before the final coding.

A pretest and posttest knowledge test consisted of 10 multiple choice questions was used to measure students' domain-specific knowledge. This survey was not related to the essay writing as such. A panel of relevant teachers in the field of educational sciences and educational technologies discussed these questions and reached to conclusions. Each correct answer was given one point and thus each student could receive 10 points at maximum for both pretest and posttest. The reliability coefficient scores for both the pretest (Cronbach's $\alpha=0.83$ ) and posttest (Cronbach's $\alpha$ $=0.87$ ) were high.

\section{Data analysis}

One-Way ANOVA test was conducted to compare the conditions in term of students' quality of peer learning processes. ANOVA test for repeated measurement was conducted to compare conditions in terms of progress of students from draft phase to revision phase in terms of their argumentative essay quality and from pretest to posttest in terms of domain-specific knowledge gain. When the difference was significant, Tukey's HSD tests were carried out as the post hoc analysis to clarify the differences among various conditions.

\section{Results}

Students' quality of peer learning processes

The results indicated a significant difference among students in four conditions in terms of their argumentative peer learning quality, $F_{(3,82)}=18.54, p<.001, \eta^{2}=0.40$ (see Table 2). The Tukey's HSD test revealed that students with the peer feedback support $(\mathrm{M}=11.18, \mathrm{SD}=3.74)$, peer feedforward support $(M=8.50, S D=4.68)$ and mixed support $(M=10.45, S D=3.17)$ significantly outperformed students in the control condition without support $(\mathrm{M}=4.09, \mathrm{SD}=1.15), p<.001$. However, there was no significant difference among the three experimental conditions $(p>.05)$.

\section{Students' quality of argumentative essay writing}

The results showed that, overall, the mean scores of students' written argumentative essay in all conditions improved significantly from draft version to revised version, Wilks $\lambda=0.40, F_{(3,82)}=$ $118.16, p<.001, \eta^{2}=0.59$ (see Table 3). The Tukey's HSD test revealed that students with peer feedback support $(\mathrm{M}=10.40, \mathrm{SD}=2.19)$, peer feedforward support $(\mathrm{M}=8.42, \mathrm{SD}=2.85)$ and mixed support $(\mathrm{M}=9.95, \mathrm{SD}=2.03)$ significantly outperformed students in the control condition without support $(\mathrm{M}=5.36, \mathrm{SD}=1.39), p<.001$. However, there was no significant difference among the three experimental conditions $(p>.05)$. 
Table 2: Students' mean scores for quality of argumentative peer learning processes $(\max =16 ; \min =0)$

\begin{tabular}{|c|c|c|c|c|c|c|c|c|}
\hline \multirow{3}{*}{$\begin{array}{l}\text { Components of a high-quality } \\
\text { peer learning }\end{array}$} & \multicolumn{8}{|c|}{ Conditions } \\
\hline & \multicolumn{2}{|c|}{ Control } & \multicolumn{2}{|c|}{ Peer feedback } & \multicolumn{2}{|c|}{ Peer feedforward } & \multicolumn{2}{|c|}{ Mixed } \\
\hline & M & $S D$ & M & $S D$ & $M$ & $S D$ & $M$ & $S D$ \\
\hline The clear position on the topic & 0.86 & 0.35 & 1.31 & 0.77 & 0.72 & 0.76 & 1.25 & 0.44 \\
\hline The introduction for the topic & 0.81 & 0.50 & 1.22 & 0.68 & 1.04 & 0.78 & 1.20 & 0.61 \\
\hline $\begin{array}{l}\text { Arguments supporting the } \\
\text { position }\end{array}$ & 1.27 & 0.55 & 1.68 & 0.47 & 1.40 & 0.73 & 1.30 & 0.47 \\
\hline $\begin{array}{l}\text { The evidence supporting the } \\
\text { position }\end{array}$ & 0.18 & 0.50 & 1.36 & 0.72 & 1.27 & 0.63 & $1 . .45$ & 0.51 \\
\hline $\begin{array}{l}\text { Arguments opposing the } \\
\text { position }\end{array}$ & 0.13 & 0.35 & 1.59 & 0.66 & 1.18 & 0.73 & 1.20 & 0.69 \\
\hline $\begin{array}{l}\text { The evidence opposing the } \\
\text { position }\end{array}$ & 0.04 & 0.21 & 1.31 & 0.77 & 1.00 & 0.75 & 1.35 & 0.48 \\
\hline $\begin{array}{l}\text { The weighing benefits and } \\
\text { drawbacks }\end{array}$ & 0.00 & 0.00 & 1.27 & 0.76 & 0.95 & 0.78 & 1.45 & 0.51 \\
\hline $\begin{array}{l}\text { The final conclusion on the } \\
\text { position }\end{array}$ & 0.77 & 0.52 & 1.40 & 0.66 & 0.90 & 0.75 & 1.25 & 055 \\
\hline Total & 4.09 & 1.15 & 11.8 & 3.74 & 8.50 & 4.68 & 10.45 & 3.17 \\
\hline
\end{tabular}

\section{Students' domain-specific knowledge learning}

The results indicated that, overall, in terms of domain-specific knowledge learning students in all four conditions improved significantly from the pretest to the posttest, Wilks $\lambda=0.36, F_{(3,82)}=$ $142.44, p<.001, \eta^{2}=0.63$. The Tukey's HSD test revealed that students with the peer feedback support $(\mathrm{M}=6.68, \mathrm{SD}=1.58)$, peer feedforward support $(\mathrm{M}=6.13, \mathrm{SD}=1.45)$ and mixed support $(\mathrm{M}=6.00, \mathrm{SD}=1.33)$ significantly outperformed students in the control group condition without support $(\mathrm{M}=4.50, \mathrm{SD}=1.79), p<.05$. There was no significant difference among the three experimental conditions $(p>.05)$.

\section{Discussions}

The overall aim of this study was to compare the effects of support for peer feedback, peer feedforward and their combination on students' peer learning processes, argumentative essay quality and domain-specific learning. Below we explain our results on the bases of our research questions:

Students' quality of peer learning processes

Students in all the three experimental conditions significantly outperformed than students in the control group condition without peer learning support with regard to their quality of peer learning processes. This implies that asking to engage in peer learning without appropriate support does not meet the potential of peer learning processes. Previous findings also suggest to support students (eg, using tutorials, checklists, question prompts, scripts, templates and sentence openers) when asking them to engage in peer learning processes (see Gielen \& De Wever, 2015; Latifi et al., 2019; Min, 2005; Noroozi et al., 2016; Noroozi, Hatami, et al., 2018; Panadero, Romero, \& Strijbos, 2013). The EduTech environment allowed us to embed different form of question prompts to support students with peer feedback, peer feedforward and their combination towards achieving the desired mode of peer learning processes. These question prompts in the 


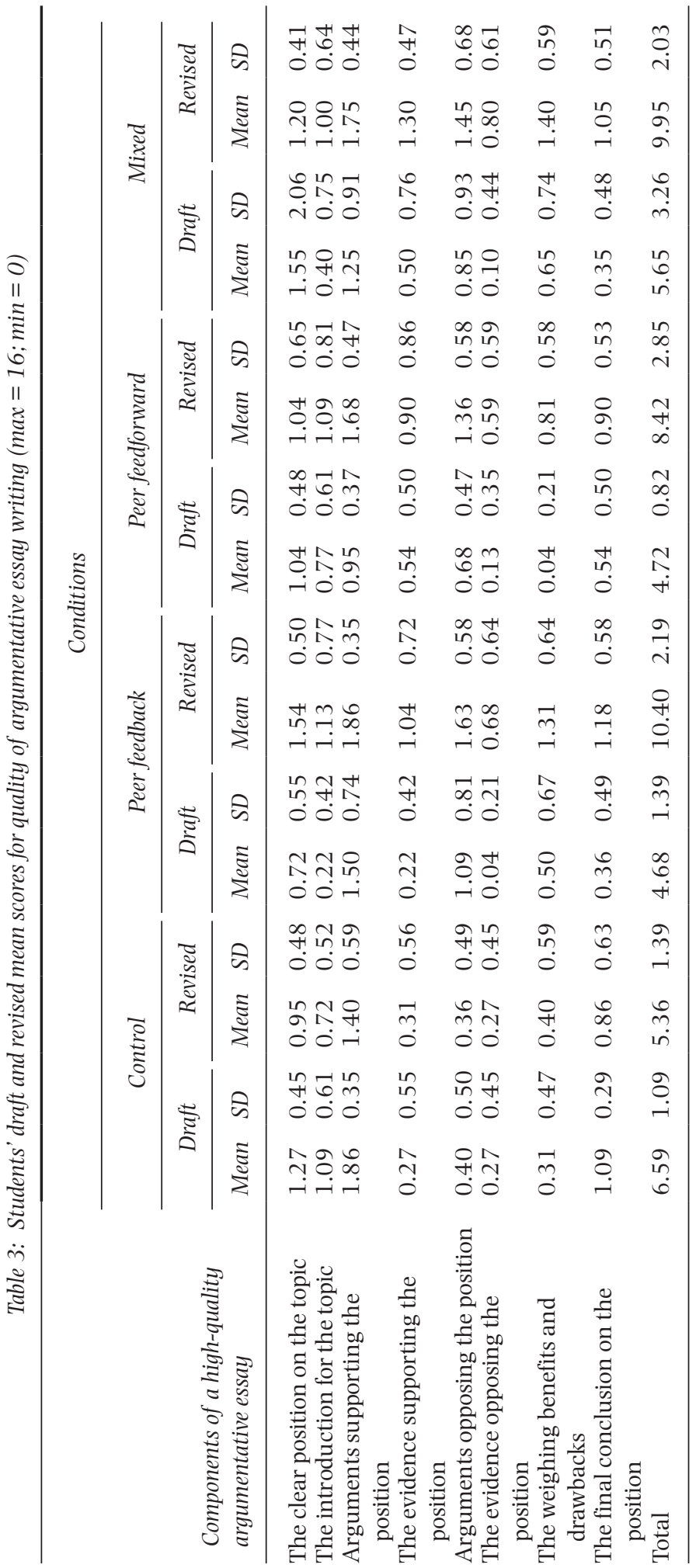


three experimental conditions provided students with a set of criteria for constructive evaluation of peers' essay by familiarizing them with the elements of a sound argumentative essay (Min, 2006). Students in the control group condition were not supported with such question prompts to provide their peers with valid and relevant points and comments during peer learning processes. Using such question prompts made students in the three experimental conditions familiar with clear assessment criteria and standards which allowed them to engage in a more relevant and structured peer learning processes than students in the control group condition. This may explain why students in the three experimental conditions outperformed students in the control group condition without support in terms of their peer learning processes.

\section{Students' quality of argumentative essay writing}

Students in the experimental conditions outperformed students in the control group condition in terms of improvement of their quality of argumentative essay from draft phase to revised phase. In other words, high-quality peer learning processes were also reflected in the argumentative essay writing of the students in the experimental conditions. This is in line with previous literature (eg, Gielen \& De Wever, 2015; Min, 2006; Noroozi et al., 2016; Noroozi \& Hatami, 2019; Noroozi, Hatami, et al., 2018; Valero Haro et al., 2018) reporting that peer learning support could also improve their argumentative essay writing. The support in the form of question prompts in the experimental conditions provided students with the opportunity to participate in high-quality peer learning processes far beyond their current level of competence which helped them learn about the essential components of an argumentative essay and how to apply this knowledge into their revised argumentative essay (Stegmann, Weinberger, \& Fischer, 2007).

The same pattern was true for providing feedback and feedforward meaning that students who provided higher quality feedback and feedforward for the learning peers wrote higher quality argumentative essays compared with those students who provided lower-quality feedback and feedforward. More specifically, students who received and provided more elaborated, justified and fruitful feedback and feedforward scored higher with regard to quality of their argumentative essays compared with those students who received and provided less elaborated, justified and fruitful feedback and feedforward. This is in line with the study of Noroozi and colleagues (2016) revealing the relations between online peer learning processes and outcomes. Students in the three experimental conditions were supported by a set of question prompts during peer learning processes which made them familiar with the components and features of a high-quality argumentative essay. This can explain why students in the three experimental conditions outperformed students in the control group condition without support in terms of their argumentative essay quality.

\section{Students' domain-specific knowledge learning}

Students in the experimental conditions outperformed students in the control group condition in terms of improvement of their domain-specific learning from pretest to posttest. In other words, high-quality peer learning processes not only were reflected in the argumentative essay writing of the students in the experimental conditions but also their domain-specific learning. This resembles previous research findings (see Nelson \& Schunn, 2009; Nicolaidou, 2013; Noroozi \& Hatami, 2019; Noroozi \& Mulder, 2017; Valero Haro et al., 2018) reporting that peer learning support could also improve students' domain-specific learning. In other words, when students engage in high-quality peer learning processes, they gain more knowledge on the topic (Noroozi et al., 2016). The question prompts embedded in the EduTech allowed students to engage in a high level of argumentative peer learning processes. Various research studies have shown that high-quality peer interaction and also writing argumentative essays on the issue at hand are 
closely related to deeper cognitive elaboration of the materials and thus to knowledge acquisition (eg, Stegmann, Wecker, Weinberger, \& Fischer, 2012; Stegmann et al., 2007).

In addition, receiving feedback from learning peers followed by justified and qualified arguments and justifications helped students acquire divergent and various perspectives on the issue at hand during peer feedback processes. Furthermore, analyzing learning peers' argumentative essays could also lead to a better reflection on the content and understanding of the topic of the study (Bayerlein, 2014). Such justifications, clarifications and elaborations of the learning materials during peer learning processes can explain why students in the three experimental conditions outperformed students in the control group condition without support in terms of their domain-specific learning.

\section{Lack of differences among the three experimental conditions}

In this study, students in the experimental conditions outperformed students in the control group condition in terms of peer learning processes, argumentative essay quality and domain-specific learning. However, there was no statistically significant difference among the three experimental conditions with regard to all the dependent variables. When engaging in peer learning processes one should not only focus on responding to the actual task with respect to the actual performance of their learning peers but also providing information on possible directions or strategies for their learning peers to attain the desired goal (see Noroozi \& Hatami, 2019). In other words, when implementing peer learning in classrooms, students should be guided in such a way to provide each other with directions and possible suggestions for improvement such as (where to next?; what to do? How to do?) (see Hattie \& Timperley, 2007).

Taking together, we expected that students in the mixed condition who were offered support for both peer feedback and peer feedforward outperform students in the other two experimental conditions who were offered support for either peer feedback or peer feedforward. The results of this study did not confirm our expectations. This could be due to the short duration of study. In this short duration study, when the two types of question prompts were combined in the mixed experimental condition, students may have arbitrarily chosen to follow one set of question prompts or parts of each sets of question prompts to comply with the requirements and completion of the task within the limited time. This could have led them ignore parts of the questions prompts for fulfilling the learning task. Such pressure on students in the mixed condition to provide both peer feedback and peer feedforward may have spoiled the richness of such natural peer learning processes (Dillenbourg \& Tchounikine, 2007).

\section{Conclusions, limitations and suggestions for future research}

This study compare the effects of support for the peer feedback, peer feedforward and their combination on students' peer learning processes, argumentative essay quality and domain-specific learning. The findings showed that various types of support embedded in the EduTech environment can improve the quality of students' argumentative peer learning processes which in turn can lead to improvement of their argumentative essay quality and domain-specific learning. The support for the peer feedback, peer feedforward and their combination guided students to analyze and evaluate various components of argumentative essays of their peers which in turn helped them to write higher quality argumentative essays and learn about the issue at hand.

Despite the superiority of the various types of support in the three experimental conditions (peer feedback, peer feedforward and their combination) over the control group condition, there was no significant difference among the experimental conditions in terms of all the dependent variables. Students with peer feedforward support would benefit the same extent as students with 
peer feedback support. That is why, Hattie and Timperley (2007) emphasize that peer learning can be more effective when the feedback is accompanied with feedforward.

There are several methodological issues that should be considered in future research. First, in this study, we analyzed and assessed the quality of students' argumentative essays and peer learning processes quantitatively. Although the coding scheme employed in this study possess the necessary psychometric parameters (ie, validity and reliability), we recommend to use qualitative measurement methods in further research to see if the outcomes would be the same or not. Furthermore, interview with participants and also detailed qualitative analysis would help us discover the extent to which and how the integration of students' feedback and feedforward comments into the peers' final argumentative essays can improve students' quality of the argumentative essays. In other words, more in-depth analysis would reflect on what makes good writing and how peer learning can be best used to improve students' writing quality.

Second, all 86 students of this study were female. We did not have any influence on this gender bias since this study was conducted in a real educational setting and this limited us from further experimentation. Scientific literature shows that males might perform differently than females in terms of argumentative peer learning and writing (Noroozi, Hatami, et al., 2018). Thus, future research could take this issue into account with a larger sample size and with a mixed group of students (in terms of gender and also different learning contexts) to further guarantee the generalizability of the results of this study.

Finally, we expected that students in the mixed condition with combined peer feedback and peer feedforward would perform better than students who were offered either one of them. This was not the case, however, and students in all three experimental conditions performed equally. We speculated that the plausible reason could be the short study duration of the study which did not allow students in the mixed condition to reflect on all the question prompts for both peer feedback and peer feedforward. Therefore, we recommend future research to be conducted in a longer duration than this study and also in different learning contexts to see to what extent the potential of offering students both feedback and feedforward in combination can be realized.

\section{Statements on open data, ethics and conflict of interest}

The data presented in this study are available upon request to the first author. Furthermore, upon request, the link to the various modules of the EduTech environment can be provided by the first author with username and password.

Ethical approvals of this study were guaranteed by the hosting institution. All the information collected from this study has been kept confidential.

In addition, the authors declare that they have no conflict of interest to disclose.

\section{References}

Bacha, N. (2010). Teaching the academic argument in a university EFL environment. Journal of English for Academic Purposes, 9(3), 229-241.

Bayerlein, L. (2014). Students' feedback preferences: How do students react to timely and automatically generated assessment feedback? Assessment \& Evaluation in Higher Education, 39(8), 916-931.

Cho, K., \& Schunn, C. D. (2007). Scaffolded writing and rewriting in the discipline: A web-based reciprocal peer review system. Computers \& Education, 48(3), 409-426.

Crowhurst, M. (1990). Teaching and learning the writing of persuasive/argumentative discourse. Canadian Journal of Education/Revue Canadienne De L'éducation, 15, 348-359. 
Dijks, M. A., Brummer, L., \& Kostons, D. (2018). The anonymous reviewer: The relationship between perceived expertise and the perceptions of peer feedback in higher education. Assessment $\&$ Evaluation in Higher Education, 1-14. https://doi.org/10.1080/02602938.2018.1447645

Dillenbourg, P., \& Tchounikine, P. (2007). Flexibility in macro-scripts for computer-supported collaborative learning. Journal of Computer Assisted Learning, 23(1), 1-13. https://doi.org/10.1111/j.1365-2729. 2007.00191.x

Earl, L. (2003). Assessment as learning: Using classroom assessment to maximize student learning. In T. R. Guskey \& R. J. Marzano (Eds.), Experts in assessment series. Thousand Oaks, CA: Corwin Press.

Gielen, M., \& De Wever, B. (2015). Structuring the peer assessment process: A multilevel approach for the impact on product improvement and peer feedback quality. Journal of Computer Assisted Learning, 31(5), $435-449$.

Hattie, J., \& Timperley, H. (2007). The power of feedback. Review of Educational Research, 77(1), 81-112.

Huisman, B., Saab, N., van den Broek, P., \& van Driel, J. (2018). The impact of formative peer feedback on higher education students' academic writing: A meta-analysis. Assessment \& Evaluation in Higher Education, 44(6), 1-18. https://doi.org/10.1080/02602938.2018.1545896

Ion, G., Barrera-Corominas, A., \& Tomàs-Folch, M. (2016). Written peer-feedback to enhance students' current and future learning. International Journal of Educational Technology in Higher Education, 13(1), 1-11. https://doi.org/10.1186/s41239-016-0017-y

Kellogg, R. T., \& Whiteford, A. P. (2009). Training advanced writing skills: The case for deliberate practice. Educational Psychologist, 44(4), 250-266.

King, A. (2002). Structuring peer interaction to promote high-level cognitive processing. Theory into Practice, 41(1), 33-39.

Latifi, S., Noroozi, O., Hatami, J., \& Biemans, H. J. A. (2019). How does online peer feedback improve argumentative essay writing and learning? Innovations in Education and Teaching International, 1-12. https:// doi.org/10.1080/14703297.2019.1687005

Leitão, S. (2003). Evaluating and selecting counterarguments: Studies of children's rhetorical awareness. Written Communication, 20(3), 269-306. https://doi.org/10.1177/0741088303257507

Lin, G. Y. (2018). Anonymous versus identified peer assessment via a Facebook-based learning application: Effects on quality of peer feedback, perceived learning, perceived fairness, and attitude toward the system. Computers \& Education, 116, 81-92.

Lin, S. S. J., Liu, E. Z. F., \& Yuan, S. M. (2001). Web-based peer assessment: Feedback for students with various thinking-styles. Journal of Computer Assisted Learning, 17(4), 420-432. https://doi. org/10.1046/j.0266-4909.2001.00198.x

Liu, N. F., \& Carless, D. (2006). Peer feedback: The learning element of peer assessment. Teaching in Higher Education, 11(3), 279-290.

Mei, W. S. (2006). Creating a contrastive rhetorical stance: Investigating the strategy of problematization in students' argumentation. RELC Journal, 37(3), 329-353. https://doi.org/10.1177/0033688206071316

Min, H.-T. (2005). Training students to become successful peer reviewers. System, 33(2), 293-308. https:// doi.org/10.1016/j.system.2004.11.003

Min, H.-T. (2006). The effects of trained peer review on EFL students' revision types and writing quality. Journal of Second Language Writing, 15(2), 118-141. https://doi.org/10.1016/j.jslw.2006.01.003

Nelson, M. M., \& Schunn, C. D. (2009). The nature of feedback: How different types of peer feedback affect writing performance. Instructional Science, 37(4), 375-401.

Nicol, D. J., \& Macfarlane-Dick, D. (2006). Formative assessment and self-regulated learning: A model and seven principles of good feedback practice. Studies in Higher Education, 31(2), 199-218.

Nicol, D., Thomson, A., \& Breslin, C. (2014). Rethinking feedback practices in higher education: A peer review perspective. Assessment \& Evaluation in Higher Education, 39(1), 102-122.

Nicolaidou, I. (2013). E-portfolios supporting primary students' writing performance and peer feedback. Computers \& Education, 68, 404-415.

Noroozi, O. (2018). Considering students' epistemic beliefs to facilitate their argumentative discourse and attitudinal change with a digital dialogue game. Innovations in Education and Teaching International, 55(3), 357-365. https://doi.org/10.1080/14703297.2016.1208112 
Noroozi, O., Biemans, H. J. A., Busstra, M. C., Mulder, M., \& Chizari, M. (2011). Differences in learning processes between successful and less successful students in computer-supported collaborative learning in the field of human nutrition and health. Computers in Human Behavior, 27(2011), 309-318.

Noroozi, O., Biemans, H., \& Mulder, M. (2016). Relations between scripted online peer feedback processes and quality of written argumentative essay. Internet and Higher Education, 31(1), 20-31.

Noroozi, O., \& Hatami, J. (2019). The effects of online peer feedback and epistemic beliefs on students' argumentation-based learning. Innovations in Education and Teaching International, 56(5), 548-557. https:// doi.org/10.1080/14703297.2018.1431143

Noroozi, O., Hatami, J., Bayat, A., van Ginkel, S., Biemans, H. J. A., \& Mulder, M. (2018). Students' online argumentative peer feedback, essay writing, and content learning: Does gender matter? Interactive Learning Environments, 28(6), 698-712. https://doi.org/10.1080/10494820.2018.1543200

Noroozi, O., Kirschner, P. A., Biemans, H. J., \& Mulder, M. (2018). Promoting argumentation competence: Extending from first-to second-order scaffolding through adaptive fading. Educational Psychology Review, 30(1), 153-176.

Noroozi, O., \& Mulder, M. (2017). Design and evaluation of a digital module with guided peer feedback for student learning biotechnology and molecular life sciences, attitudinal change, and satisfaction. Biochemistry and Molecular Biology Education, 45(1), 31-39.

Panadero, E., Romero, M., \& Strijbos, J.-W. (2013). The impact of a rubric and friendship on peer assessment: Effects on construct validity, performance, and perceptions of fairness and comfort. Studies in Educational Evaluation, 39(4), 195-203. https://doi.org/10.1016/j.stueduc.2013.10.005.

Patchan, M. M., \& Schunn, C. D. (2015). Understanding the benefits of providing peer feedback: How students respond to peers' texts of varying quality. Instructional Science, 43(5), 591-614. https://doi. org/10.1007/s11251-015-9353-x

Rahimi, M. (2013). Is training student reviewers worth its while? A study of how training influences the quality of students' feedback and writing. Language Teaching Research, 17(1), 67-89. https://doi. org/10.1177/1362168812459151

Rollinson, P. (2005). Using peer feedback in the ESL writing class. ELT Journal, 59(1), 23-30. https://doi. org/10.1093/elt/cci003

Schneer, D. (2014). Rethinking the argumentative essay. TESOL Journal, 5(4), 619-653.

Stegmann, K., Wecker, C., Weinberger, A., \& Fischer, F. (2012). Collaborative argumentation and cognitive elaboration in a computer-supported collaborative learning environment. Instructional Science, 4O(2), 297-323.

Stegmann, K., Weinberger, A., \& Fischer, F. (2007). Facilitating argumentative knowledge construction with computer-supported collaboration scripts. International Journal of Computer-Supported Collaborative Learning, 2(4), 421-447.

Topping, K. J. (2005). Trends in peer learning. Educational Psychology, 25(6), 631-645. https://doi. org/10.1080/01443410500345172

Topping, K. J. (2009). Peer assessment. Theory into Practice, 48, 20-27.

Toulmin, S. (1958). The uses of argument. Cambridge, UK: Cambridge University Press.

Tsui, A. B., \& Ng, M. (2000). Do secondary L2 writers benefit from peer comments? Journal of Second Language Writing, 9(2), 147-170.

Valero Haro, A., Noroozi, O., Biemans, H. J. A., \& Mulder, M. (2018). The effects of an online learning environment with worked examples and peer feedback on students' argumentative essay writing and domain-specific knowledge acquisition in the field of biotechnology. Journal of Biological Education, 53(4), 390-398. https://doi.org/10.1080/00219266.2018.1472132

Van den Boom, G., Paas, F., \& van Merriënboer, J. J. G. (2007). Effects of elicited reflections combined with tutor or peer feedback on self-regulated learning and learning outcomes. Learning and Instruction, 17(5), $532-548$.

Vygotsky, L. (1962). Thought and language. Cambridge: Cambridge University Press.

Vygotsky, L. S. (1978). Mind in society: The development of higher psychological processes. Cambridge, MA: Harvard University Press. 
Wingate, U. (2012). 'Argument!' helping students understand what essay writing is about. Journal of English for Academic Purposes, 11(2012), 145-154.

Wood, N. V. (2001). Perspectives on argument. New Jersey: Prentice Hall.

$\mathrm{Wu}, \mathrm{S}$. M. (2006). Creating a contrastive rhetorical stance: Investigating the strategy of problematization in students' argumentation. RELC Journal, 37(3), 329-353.

Xiao, Y., \& Lucking, R. (2008). The impact of two types of peer assessment on students' performance and satisfaction within a Wiki environment. The Internet and Higher Education, 11(3-4), 186-193.

Yang, Y. F. (2010). Students' reflection on online self-correction and peer review to improve writing. Computers \& Education, 55(3), 1202-1210.

\section{Supporting Information}

Additional supporting information may be found online in the Supporting Information section at the end of the article. 